\title{
OXIDATIVE STABILITY OF MAYONNAISE PREPARED USING VIRGIN COCONUT OIL/FISH OIL BLEND
}

\author{
Umesh Patil $^{1}$ and Soottawat Benjakul ${ }^{1 凶}$ \\ ${ }^{I}$ Department of Food Technology, Faculty of Agro-Industry, \\ Prince of Songkla University, Hat Yai, Songkhla, Thailand, 90110 \\ $\otimes_{\text {soottawat.b@psu.ac.th }}$ \\ https://doi.org/10.34302/crpjifst/2020.12.1.13 \\ Article history: \\ Received: \\ 30 June 2019 \\ Accepted: \\ 2 January 2020 \\ Keywords: \\ Mayonnaise; \\ Virgin coconut oil; \\ Storage; \\ Lipid oxidation. \\ ABSTRACT \\ Chemical changes in mayonnaise prepared using virgin coconut oil (VCO)/ \\ fish oil (FO) blends at different ratios (95:5, 90:10, 85:15, v/v) were \\ monitored throughout 30 days of storage at ambient temperature in \\ comparison with the mayonnaise prepared using soybean oil (SO). Free fatty \\ acid contents in all mayonnaise were increased after the storage of 30 days. \\ Peroxide value, thiobarbituric acid reactive substances, $\rho$-anisidine value \\ and total oxidation values of mayonnaise prepared using VCO were lowest \\ during the storage, indicating the highest oxidative stability among all \\ samples. Lipid oxidation was increased with extended storage time and \\ higher level of FO added in mayonnaise. Highest lipid oxidation took place \\ in mayonnaise containing SO after the storage of 30 days. At day 0, linoleic \\ acid $(50.07 \%)$ was the dominant fatty acid in SO containing mayonnaise, \\ whereas lauric acid (47.05\%) was predominant in VCO containing \\ mayonnaise. Docosahexaenoic acid (DHA) and eicosapentaenoic acid \\ (EPA) were found in mayonnaise prepared using VCO/FO blends. Lauric \\ acid, myristic acid, EPA and DHA were decreased in all samples after the \\ storage of 30 days. Volatile compounds, mainly hexanal, were increased \\ after storage of 30 days. Mayonnaise prepared from VCO/FO (90:10) blend \\ had no differences in sensorial property with that containing SO. Thus, \\ $\mathrm{VCO} / \mathrm{FO}$ (90:10) blend could be used to prepare mayonnaise with health \\ benefit and the increased oxidative stability.
}

\section{Introduction}

Mayonnaise is one of the most favorite sauces in the world (Huang et al., 2016). It is oilin-water emulsion with acidic $\mathrm{pH}$, comprising three components: vinegar/water as a continuous phase, $70-80 \%$ oil as a dispersed phase and egg yolk used as an emulsifier ( $\mathrm{Li}$ et al., 2014). Mayonnaise is oil containing product, in which soybean oil is commonly used. Basically, soybean oil is highly prone to lipid oxidation because of its unsaturated fatty acids. As a result, undesirable components e.g. reactive aldehydes and free radicals are formed (Gorji et al., 2016). To conquer the problem or prevent lipid oxidation, synthetic or natural antioxidants have been generally added in mayonnaise (Meyer and Jacobsen, 1996; Jacobsen et al., 2001). However, synthetic antioxidants e.g. butylated hydroxy toluene (BHT), butylated hydroxy anisole (BHA) and ethylene diamine tetraacetic acid (EDTA) have a bad impression due to their toxic effects, particularly when high concentrations are used (Martinez-Tome et al., 2001).

Fish oil (FO) has been well known for health-promoting benefits. Therefore, health experts recommend a higher consumption of fish oil rich in polyunsaturated fatty acids (PUFAs), mostly docosahexaenoic acid (DHA) and eicosapentaenoic acid (EPA) (Hartvigsen et al., 2000). Incorporation of PUFAs into foods 
can be of consumers' health benefit (Gorji et al., 2016). Susceptibility of lipids towards oxidation is determined by the location and number of double bonds. Generally, unsaturated lipids are prone to lipid oxidation than saturated counterpart (McClements and Decker, 2000).

Virgin coconut oil (VCO) comprises medium chain fatty acids (MCFAs), mostly lauric acid (Patil and Benjakul, 2019b). By reason of various health benefits and high stability, VCO has gained the interest for processor and consumer (Patil and Benjakul, 2018). Incorporation of VCO in combination with FO could be a means to prepare a functional mayonnaise. The balance between saturated and unsaturated oil would achieve both targets: health promotion and oxidative stability of resulting mayonnaise. Nevertheless, different types of oil in mayonnaise may give different sensory and physical characteristics. Therefore, this work was undertaken to incorporate VCO and FO at different ratios into mayonnaise. Oxidative stability and physical properties of resulting mayonnaises were examined throughout the storage of 30 days in comparison with that prepared using soybean oil (SO).

\section{Materials and methods}

\subsection{Chemicals}

Nile blue A, ammonium thiocyanate, $\rho$ anisidine, sodium hydroxide, and sodium chloride were procured from Sigma (St. Louis. MO, USA). Isooctane, sodium dodecyl sulfate and trichloroacetic acid were obtained from Merck (Darmstadt, Germany). Ethanol, methanol, chloroform, propanol, acetic acid, petroleum ether, n-hexane and hydrochloric acid were procured from Lab-Scan (Bangkok, Thailand). Eggs and soybean oil (SO) were bought from a supermarket in Hat Yai, Songkhla, Thailand.

\subsection{Preparation of virgin coconut oil (VCO)}

VCO was produced according to the method of Patil and Benjakul (2019b). Coconut milk was firstly hydrolyzed with partially purified seabass protease (PPSP) (10 units/g protein) at $60{ }^{\circ} \mathrm{C}$ for 60 mins followed by low speed centrifugation $(3585 \times \mathrm{g})$ to obtain cream. The cream was frozen at $-20{ }^{\circ} \mathrm{C}$ for $6 \mathrm{hr}$ and then thawed at room temperature $\left(30 \pm 2{ }^{\circ} \mathrm{C}\right)$ for $1 \mathrm{hr}$. Five freeze-thawing cycles were repeated. Finally, cream was centrifuged at high speed $(8000 \times \mathrm{g})$ to obtain VCO.

\subsection{Preparation of fish oil from seabass viscera}

Whole viscera of seabass were purchased from a local market in Hat Yai. Polyethylene bag was used to pack the samples and ice was used to store it using an ice/sample ratio of 2:1 (w/w). Thereafter, samples were carried to the Department of Food Technology, Prince of Songkla University within $30 \mathrm{~min}$. After arrival, depot fat from viscera was separated immediately from other internal organs such as stomach, liver, intestine and pyloric caeca. The obtained depot fat was chopped into small pieces with knife and ground with a blender (National, MX-T2GN, Taipei, Taiwan). The ground sample was used for oil extraction.

\subsubsection{Extraction of oil from depot fat}

Fish oil was extracted from depot fat following the method of Patil and Benjakul (2019a). Visceral depot fat $(100 \mathrm{~g})$ was transferred into a round bottom flask equipped with a rotary evaporator (EYELA, N-1000, Tokyo Rikakikai, Co., Ltd., Tokyo, Japan). The extraction was performed at $70{ }^{\circ} \mathrm{C}$ for 20 mins under vacuum. After extraction, oil was placed in an Erlenmeyer flask containing anhydrous sodium sulfate (approximately 3-4 g), shaken well and decanted into a centrifuge tube through a Whatman No. 4 filter paper. The mixture was centrifuged at $10,000 \times \mathrm{g}$ for $20 \mathrm{mins}$ at $4{ }^{\circ} \mathrm{C}$ using a refrigerated centrifuge (CR22N, Hitachi, Hitachi Koki Co., Ltd., Tokyo, Japan). Pasteur pipette was used to collect oil. The oil sample was transferred to the amber bottles and purged with $\mathrm{N}_{2}$ gas. The amber bottles were capped tightly and kept at $-40{ }^{\circ} \mathrm{C}$ until further use.

\subsection{Preparation of mayonnaise}

Mayonnaise was prepared following the method of Patil and Benjakul (2019a). Formulation ( $\%$ on weight basis) included $8 \%$ fresh egg yolk, $4 \%$ vinegar, $1 \%$ salt, $14 \%$ sugar, $3 \%$ distilled water and $70 \%$ oil. For oil samples, 
VCO $(100 \%)$ or VCO/FO blends with different VCO: FO ratios $(95: 5,90: 10,85: 15, \mathrm{v} / \mathrm{v})$ were used. Soybean oil (100\%) was used as the reference. Mayonnaise samples were designated as S: soybean oil $(100 \%), \mathrm{V}$ : VCO $(100 \%), \mathrm{V}-$ F5: VCO $(95 \%)+$ FO (5\%), V-F10: VCO (90\%) + FO (10\%), V-F15: VCO $(85 \%)+$ FO $(15 \%)$. The resulting mayonnaise samples were used for further analysis.

\subsection{Sensory evaluation}

For sensory evaluation of all samples, $9-$ point hedonic scale was used; 9 is the most likeness and 1 is the most dislikeness (Meilgaard et al., 2006). Fifty panelists were recruited for sensory evaluation. They were the staffs and students from the Department of Food Technology, who were familiar with mayonnaise. The samples were served at room temperature with freshly made bread. Appearance, color, odor, flavor, texture, and overall likeness were evaluated. Panelists were asked to rinse their mouth between the samples using mineral water.

\subsection{Chemical changes of mayonnaise during the storage of 30 days}

Mayonnaise samples containing SO, VCO and $\mathrm{VCO} / \mathrm{FO}$ blends at different ratios were analyzed during storage of 30 days. All mayonnaise samples were kept in zip lock bag and stored at room temperature $\left(30-32^{\circ} \mathrm{C}\right)$ in the incubator (Memmert, Schwabach, Germany). Oil from mayonnaise samples was extracted every 5 days during the storage for analysis.

\subsubsection{Extraction of oil from mayonnaise}

The oil was extracted from mayonnaise sample using the method of Bligh and Dyer method (Bligh and Dyer, 1959). Obtained oil was transferred into amber bottle, flushed with $\mathrm{N}_{2}$ gas and used for further analysis.

2.6.2. Determination of free fatty acid content (FFA)

Free fatty acid content (FFA) was determined following the method as described by Patil et al. (2016).

\subsubsection{Measurement of lipid oxidation products}

Lipid oxidation products in mayonnaise samples were determined. Peroxide values (PV), $\rho$-anisidine values (AnV) and thiobarbituric acid reactive substances (TBARS) values were measured following the method tailored by Takeungwongtrakul et al. (2012) and Patil et al. (2016). Totox value was calculated by the following formula: Totox value $=2 \mathrm{PV}+\mathrm{AnV}$ (Huimin et al., 2014).

\subsubsection{Analysis of fatty acid profiles}

Oil samples extracted from mayonnaise at day 0 and day 30 were determined for fatty acid profile following the method described by Muhammed et al. (2015). Fatty acid content was calculated, based on the peak area ratio and expressed as g fatty acid/100g oil.

\subsection{Determination of volatile compounds}

Mayonnaise sample rich in both medium chain fatty acid and PUFA, with the likeness score equivalent to that of reference sample $(\mathrm{S})$ was collected at day 0 and 30 for analysis of volatiles. Volatile compounds were determined using a solid-phase micro-extraction gas chromatography mass spectrometry (SPMEGC-MS) as described by Sae-leaw and Benjakul (2017). The volatile compounds were expressed as abundance of each identified compound.

\subsection{Statistical analysis}

Experiments were carried out in triplicate using three different lots of samples. Data were subjected to analysis of variance (ANOVA). Comparison of means was carried out by the Duncan's multiple range test. T-test was used for pair comparison (Steel and Torrie, 1980). Statistical analysis was performed using the Statistical Package for Social Science (SPSS 11.0 for Windows, SPSS Inc., Chicago, IL, USA).

\section{Results and discussions}

\subsection{Sensory characteristics}

Likeness score of mayonnaise prepared using $\mathrm{SO}, \mathrm{VCO}$ and $\mathrm{VCO} / \mathrm{FO}$ blends with different ratios is presented in Table 1. Higher likeness scores for appearance and color were obtained for $S$ sample $(\mathrm{p}<0.05)$. However, appearance, color, and texture likeness scores were decreased by incorporation of $\mathrm{VCO}$ and $\mathrm{VCO} / \mathrm{FO}$ blends. 
Table 1. Likeness score of mayonnaise containing different oils.

\begin{tabular}{|l|l|c|c|c|c|c|}
\hline Samples & Appearance & Color & Odor & Flavor & Texture & Overall \\
\hline S & $8.47 \pm 0.51 \mathrm{a}$ & $8.50 \pm 0.63 \mathrm{a}$ & $6.90 \pm 1.30 \mathrm{a}$ & $7.00 \pm 0.79 \mathrm{a}$ & $7.87 \pm 0.63 \mathrm{a}$ & $7.57 \pm 0.97 \mathrm{a}$ \\
\hline V & $7.00 \pm 0.79 \mathrm{~b}$ & $7.07 \pm 0.98 \mathrm{~b}$ & $7.37 \pm 0.67 \mathrm{a}$ & $7.73 \pm 0.94 \mathrm{a}$ & $6.83 \pm 0.99 \mathrm{~b}$ & $7.43 \pm 0.89 \mathrm{a}$ \\
\hline V-F5 & $7.57 \pm 0.73 \mathrm{~b}$ & $7.33 \pm 1.03 \mathrm{~b}$ & $6.87 \pm 0.94 \mathrm{a}$ & $7.67 \pm 1.06 \mathrm{a}$ & $7.00 \pm 0.91 \mathrm{~b}$ & $7.10 \pm 0.61 \mathrm{a}$ \\
\hline V-F10 & $7.47 \pm 0.82 \mathrm{~b}$ & $7.60 \pm 1.07 \mathrm{~b}$ & $6.87 \pm 0.90 \mathrm{a}$ & $7.07 \pm 0.94 \mathrm{a}$ & $7.13 \pm 0.90 \mathrm{~b}$ & $7.07 \pm 0.53 \mathrm{a}$ \\
\hline V-F15 & $7.73 \pm 0.98 \mathrm{~b}$ & $7.50 \pm 1.22 \mathrm{~b}$ & $5.57 \pm 0.57 \mathrm{~b}$ & $6.00 \pm 0.95 \mathrm{~b}$ & $7.30 \pm 0.95 \mathrm{~b}$ & $5.77 \pm 0.97 \mathrm{~b}$ \\
\hline
\end{tabular}

S: mayonnaise containing soybean oil, V: mayonnaise containing virgin coconut oil (VCO), V-F5: mayonnaise containing VCO (95\%) + fish oil (5\%), V-F10: mayonnaise containing VCO (90\%) + fish oil (10\%), V-F15: mayonnaise containing $\mathrm{VCO}(85 \%)+$ fish oil $(15 \%)$.

Values are mean \pm standard deviation $(n=50)$.

Different lowercase letters in the same column indicate significant difference $(\mathrm{p}<0.05)$

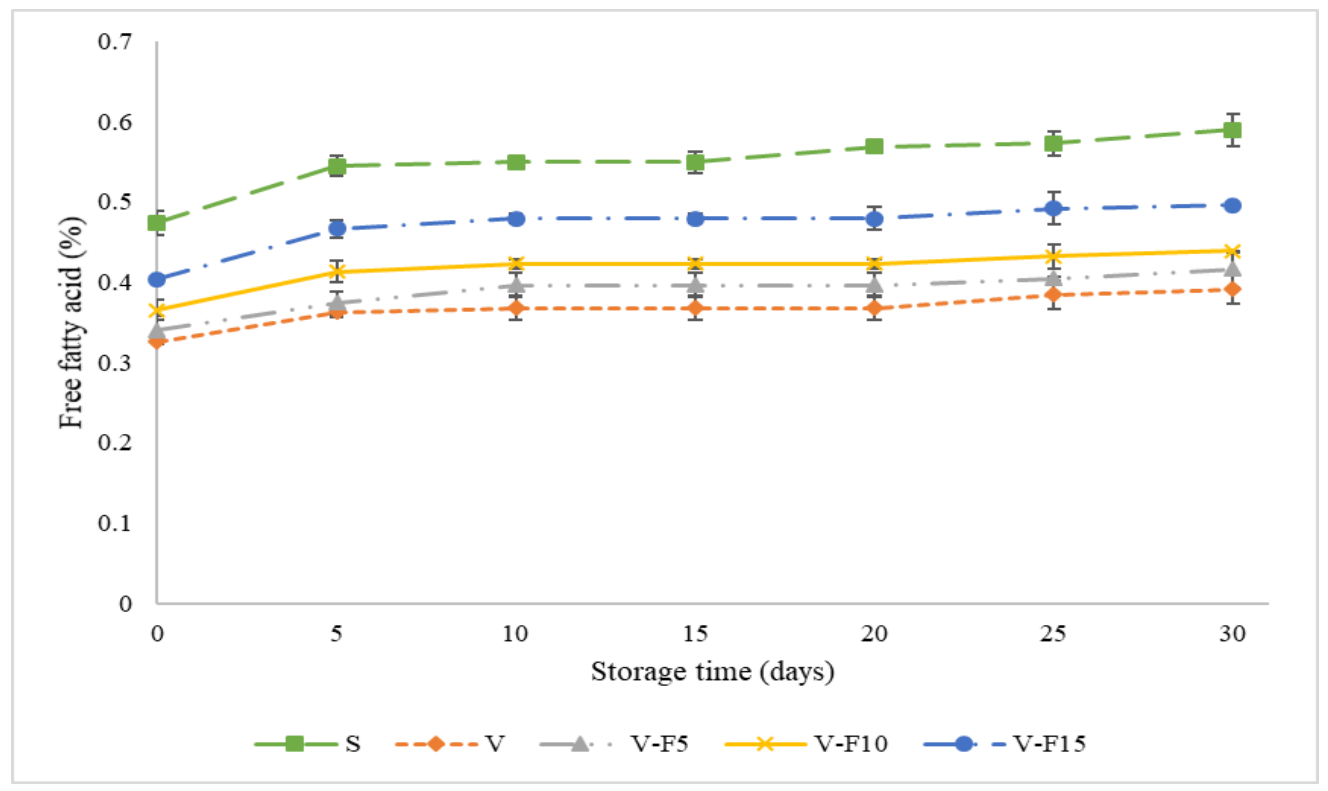

Figure 1.Free fatty acid (FFA) content of mayonnaise containing different oils during the storage of 30 days at room temperature. Bars represent standard deviations $(n=3)$.

S: mayonnaise containing soybean oil, V: mayonnaise containing virgin coconut oil (VCO), V-F5: mayonnaise containing VCO (95\%) + fish oil (5\%), V-F10: mayonnaise containing VCO (90\%) + fish oil (10\%), V-F15: mayonnaise containing VCO $(85 \%)+$ fish oil $(15 \%)$.

For odor likeness score, no difference was observed between $\mathrm{S}, \mathrm{V}, \mathrm{V}-\mathrm{F} 5$ and V-F10 samples ( $\mathrm{p}>0.05)$. Nonetheless, V-F15 showed lower score for odor likeness $(\mathrm{p}<0.05)$. The results demonstrated that VCO might be able to mask fishy odor when FO up to $10 \%$ was used. At high concentration of FO (15\%), panelists could detect the fishy odor in the mayonnaise sample. Therefore, low likeness score was obtained. Lowest flavor likeness score was also gained for $\mathrm{V}-\mathrm{F} 15$ sample $(\mathrm{p}<0.05)$. It was noticed that there was no difference between $\mathrm{S}$ and V-F10 ( $>$ >0.05). VCO has natural distinctive coconut odor and flavor (Patil et al., 2016). Results suggested that incorporation of VCO was able to improve the flavor of mayonnaise containing FO at low content but it was unable to mask the flavor of fish oil when highest level of FO (15\%) was used. For texture likeness, the highest score was found for $\mathrm{S}$ sample $(p<0.05)$. No difference between mayonnaise containing $\mathrm{VCO}$ and $\mathrm{VCO} / \mathrm{FO}$ 
blends was attained $(\mathrm{p}>0.05)$. The difference in texture between $\mathrm{S}$ sample and other samples might be governed by different fatty acid compositions. VCO rich in saturated fatty acids (Patil et al., 2016) became solidified. This might increase the viscosity or consistency of samples. The overall likeness was decreased when FO added was at levels more than $10 \%(\mathrm{p}<0.05)$. Nevertheless, no difference was observed among the rest of samples $(\mathrm{p}>0.05)$. The results suggested that VCO could be used instead of SO for the production of mayonnaise. Additionally, FO could be added up to $10 \%$ in VCO/FO blend (V-F10) for mayonnaise preparation. To increase the level of FO, the masking agent or potential removal of off-odor, particularly fishy odor, should be implemented prior to making the blend for mayonnaise preparation.

\subsection{Free fatty acid (FFA)}

FFA contents of mayonnaise prepared using SO, VCO and different VCO/FO blends throughout the storage of 30 days at room temperature are depicted in Figure 1. At day 0, all mayonnaise samples showed different FFA content. The lowest FFA content was found in V sample $(\mathrm{p}<0.05)$. Generally, VCO has low FFA content (Patil et al., 2016). FFA content was increased with increasing FO level in the blends. Some FFA were presented in FO, used for the preparation of blends for mayonnaise. Therefore, increasing concentration of FO eventually increased FFA content of the resulting mayonnaise. FFA content was gradually increased after storage of 5 days in all the samples $(\mathrm{p}<0.05)$. During the storage, all samples showed the similar pattern, in which no drastic change was observed. FFA content of $\mathrm{V}$ sample was lowest amongst all samples throughout the storage of 30 days $(p<0.05)$. The result suggested that the ester bonds of triglyceride were hydrolyzed at lower rate. However, significant difference was noticeable between day 0 and day 30 for all the samples ( $\mathrm{p}<0.05$ ), probably due to the microbial activity. Lactic acid bacteria (acid tolerant) might exist in mayonnaise (continuous phase) (Kishk and Elsheshetawy, 2013). Moreover, these increases were more likely attributed to the hydrolytic enzyme, which exists in eggs (Abu-Salem and Abou-Arab, 2008). The results suggested that type of oil used for preparation of mayonnaise could affect the FFA content of resulting mayonnaise at the beginning and after the storage.

\subsection{Oxidative stability of mayonnaise during storage}

\subsubsection{Peroxide value (PV)}

Changes in PV of mayonnaise prepared using SO, VCO and different VCO: FO blends throughout the storage of 30 days are shown in Figure 2 (A). At day 0, all mayonnaise samples showed different PV. It was lowest in V sample $(p<0.05)$. The highest PV was observed for $S$ sample, compared to other samples $(\mathrm{p}<0.05)$. $\mathrm{PV}$ is generally employed to measure lipid oxidation at the initial stage, where hydroperoxides are formed. For all the samples, PVs were continuously increased with increasing storage time $(\mathrm{p}<0.05)$. The increase in PV of all samples suggested that the samples were in propagation stage of lipid oxidation, while decomposition of hydroperoxides took place at a lower rate. Among all the samples, S sample showed the highest PV throughout the storage than those containing $\mathrm{VCO}$ or $\mathrm{VCO} / \mathrm{FO}$ blends $(p<0.05)$. In general, mayonnaise is susceptible to lipid oxidation because of their large surface area of oil droplets which facilitates the interactions between the oil, water and air (Gorji et al., 2016). McClements and Decker (2000) documented that oxidation of lipid is usually started at oil-in-water interface, where pro-oxidants such as transition metals in the continuous phase are able to interact with the hydroperoxides situated at the surface of droplet. Moreover, the $\mathrm{pH}$ is the main factor affecting oxidation of lipid in mayonnaise. In mayonnaise, as the emulsifier, egg yolk is used. Yolk contained a high amount of iron $(734 \mu \mathrm{M})$ (Jacobsen, 1999). The iron is able to make cation bridges between the protein phosvitin and other components at $\mathrm{pH}$ 6. At the low $\mathrm{pH}(3.8-4)$ found in the mayonnaise, the bridges of iron between low-density lipoprotein and phosvitin are destroyed and the iron is released, leading to enhanced oxidation of lipid (Jacobsen, 1999). 
The lowest increase in PV was observed in the $\mathrm{V}$ sample, compared to $\mathrm{PV}$ of all samples $(\mathrm{p}<0.05)$, indicating that $\mathrm{VCO}$ was less prone to lipid oxidation. This was plausibly owing to the low unsaturated fatty acid content (Patil et al., 2016). However, PV was increased with increasing concentration of $\mathrm{FO}$ in $\mathrm{VCO} / \mathrm{FO}$ blend. This might be caused by the increase in unsaturated fatty acids, which were susceptible to oxidation. The results suggested that differences in PV between mayonnaises with different oils more likely resulted from differences in their chemical structure and fatty acid compositions.

\subsubsection{TBARS}

TBARS values of mayonnaise prepared using $\mathrm{SO}, \mathrm{VCO}$ and $\mathrm{VCO} / \mathrm{FO}$ blends at different ratios during 30 days of storage are depicted in Figure 2 (B).

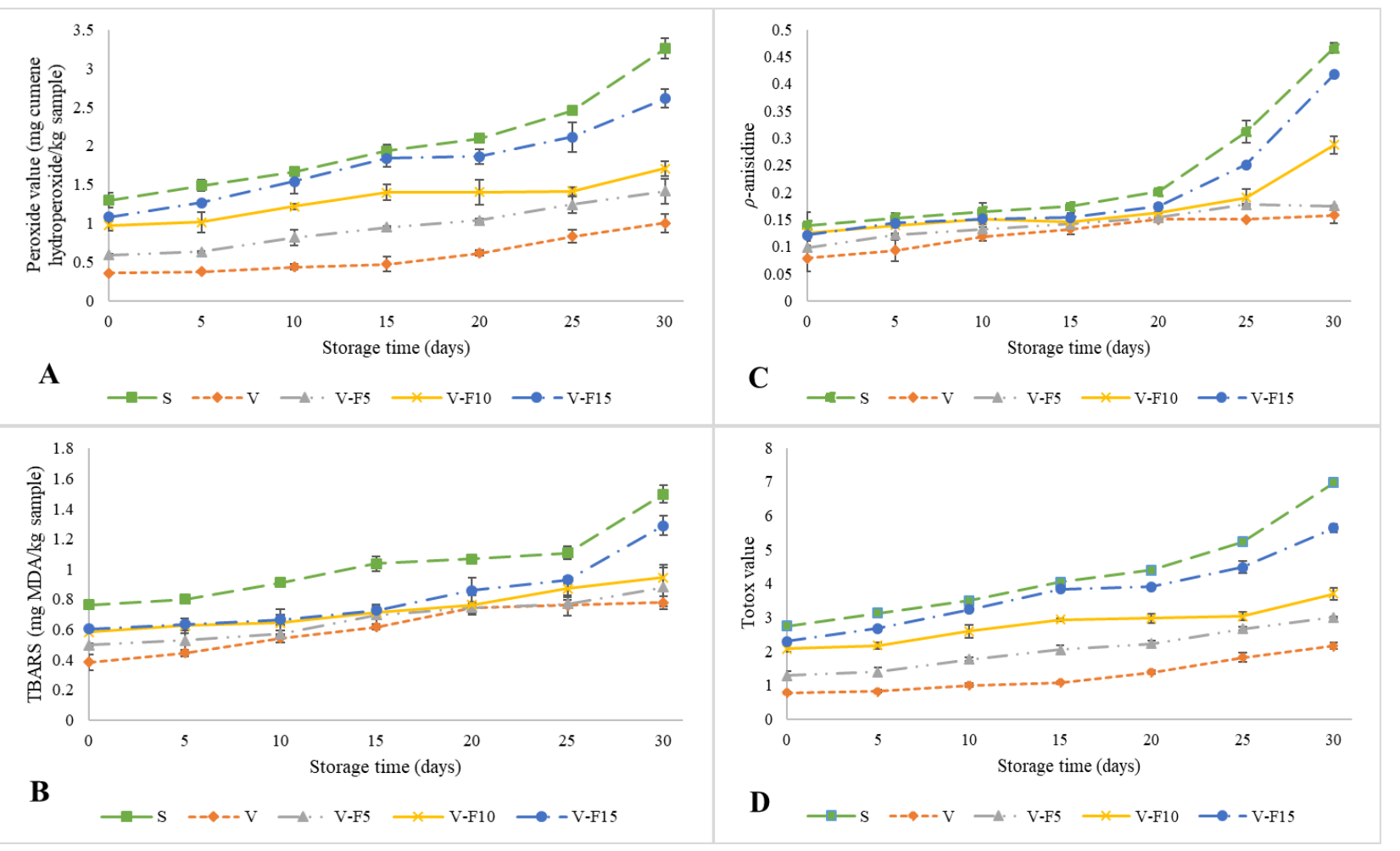

Figure 2: Peroxide value (PV) (A), thiobarbituric acid reactive substances (TBARS) (B), $\rho$-anisidine value $(\mathrm{AnV})(\mathrm{C})$ and.totox value (D) of mayonnaise containing different oils during the storage of 30 days at room temperature. Bars represent standard deviations $(n=3)$

$\mathrm{S}$ : mayonnaise containing soybean oil, V: mayonnaise containing virgin coconut oil (VCO), V-F5: mayonnaise containing VCO (95\%) + fish oil (5\%), V-F10: mayonnaise containing VCO (90\%) + fish oil (10\%), V-F15: mayonnaise containing $\mathrm{VCO}(85 \%)+$ fish oil $(15 \%)$.

TBARS values of all samples were continuously increased with extended storage time $(\mathrm{p}<0.05)$. Compared to all other samples, the $\mathrm{S}$ sample showed the higher TBARS values throughout 30 days of storage $(\mathrm{p}<0.05)$. Generally, lipids with increasing TBARS value suggested that secondary lipid oxidation products were formed in samples. TBARS value is an index of decomposition of hydroperoxides into the secondary oxidation products in the later stages of lipid oxidation (Sae-leaw and Benjakul, 2017). Hydroperoxides are decomposed to malonaldehyde, which contributes to off-flavor of oxidized lipids (Zhang et al., 2013). As storage time increased, some prooxidants could accelerate lipid oxidation at higher extent. Conversely, the lowest TBARS values were observed for $\mathrm{V}$ 
sample throughout 30 days. The results reconfirmed that VCO in mayonnaise was less prone to lipid oxidation. The slight difference was observed between TBARS values of samples added with FO until day 25. Nonetheless, the sharp increase in TBARS was found in V-F15 at day $30(\mathrm{p}<0.05)$. Overall, PVs were much lower than that reported by Chotphruethipong and Benjakul (2017) for mayonnaise enriched with fish oil. The result suggested that lipid oxidation rate was dependent on the type of oil used for the preparation of mayonnaise.

\subsection{3. $\rho$-anisidine values (AnV)}

$\mathrm{AnV}$ of mayonnaise prepared with $\mathrm{SO}, \mathrm{VCO}$ and $\mathrm{VCO} / \mathrm{FO}$ blends throughout the storage of 30 days is shown in Figure 2 (C). All samples had slight increase in AnV until day $20(\mathrm{p}<0.05)$. Thereafter, S, V-F15 and V-F10 samples had an apparent increase in AnV till the end of storage $(\mathrm{p}<0.05)$. S sample showed the highest $\mathrm{AnV}$, as compared to other samples throughout 30 days of storage $(p<0.05)$. The increase in $\mathrm{AnV}$ suggested the development of the secondary lipid oxidation products, mainly non-volatile compounds (mostly 2,4-alkadienals and 2alkenals) in lipids (Choe and Min, 2006). When comparing AnV of all the samples at day 0, the lowest AnV was observed for the $\mathrm{V}$ sample, whereas the highest $\mathrm{AnV}$ was found in the $\mathrm{S}$ sample $(p<0.05)$. The results showed that SO might contain some oxidative products at the beginning or during mayonnaise preparation. Overall, AnVs were much lower than that reported by Chotphruethipong and Benjakul (2017) for mayonnaise enriched with fish oil. The difference was most likely caused by the difference in oils used. Chotphruethipong and Benjakul (2017) prepared mayonnaise using SO blended with FO at ratio of SO:FO (90:10 v/v). The secondary oxidation products are important in food products for human consumption, since usually they have strong odor, while primary lipid oxidation products are flavorless and colorless (Osborn and Akoh, 2004). McClements and Decker (2000) documented that lipid oxidation of oil is affected by its chemical structure, mainly, location and number of double bonds. The results suggested that
VCO used for mayonnaise was able to retard lipid oxidation of mayonnaise.

\subsubsection{Total oxidation value (Totox value)}

Totox value measures hydroperoxides as well as their breakdown products and gives a well estimation of the progressive oxidative deterioration of oil (Shahidi and Zhong, 2005). For all the samples, the Totox value was increased with extended storage time $(\mathrm{p}<0.05)$. $\mathrm{S}$ sample showed the highest increase in Totox value $(p<0.05)$. Conversely, the sample containing VCO showed the lowest totox value throughout 30 days of storage, compared to others $(p<0.05)$. Overall, a similar trend was noticed in comparison with PVs. Totox value was calculated from PV and AnV. Primary oxidation products and secondary oxidation products, together with free radicals, constitute the basis for measuring the oxidative deterioration of mayonnaise (Shahidi and Zhong, 2005). Toxic reaction products are generated due to the oxidation of lipids in mayonnaise (Coupland and McClements, 1996). Unaccepted off-flavors decreased shelf-life of mayonnaise (Alemán et al., 2015). In general, mayonnaise showed high oxidative stability when VCO was used, while FO at higher ratio increased oxidation.

\subsection{Fatty acid composition}

Fatty acid compositions of mayonnaise prepared with $\mathrm{SO}, \mathrm{VCO}$ and $\mathrm{VCO} / \mathrm{FO}$ blends at day 0 and day 30 are given in Table 2 . At day 0 , fatty acid composition of $\mathrm{S}$ sample was observed to be different from $\mathrm{V}$ sample and those containing VCO/FO blend. In S sample, linoleic acid $(50.07 \%)$ was the predominant fatty acid. Oleic acid (24.18\%) and palmitic acid (11.16\%) were also found. The results were in agreement with previous report for fatty acid composition of mayonnaise prepared using $\mathrm{SO}$, in which linoleic acid $(50.4 \%)$, oleic acid $(26.1 \%)$ and palmitic acid (11.6\%) were documented (Enig et $a l ., 1983)$. For $\mathrm{V}$ sample, lauric acid (47.05\%) was predominant fatty acid, and myristic acid $(19.57 \%)$ and palmitic acid $(9.55 \%)$ were also present. Patil et al. (2016) documented that VCO predominantly comprised medium chain fatty acids (MCFA), mainly lauric acid (49.74- 
$51.18 \%$ ), followed by myristic acid (18.70$19.84 \%)$. VCO with MCFA, mainly lauric acid, is responsible for health benefits (Patil and Benjakul, 2018). FO extracted from seabass visceral depot blended with VCO showed the marked difference in fatty acid composition in the resulting mayonnaise. Sae-leaw and Benjakul (2017) documented that oil extracted from depot fat of seabass viscera contained oleic acid $(25.49 \%)$, palmitic acid $(21.8 \%)$, linoleic acid (13.84 \%), docosahexaenoic (DHA) $(6.91 \%)$ and eicosapentaenoic (EPA) (2.09\%). Saturated fatty acid, mainly lauric acid and myristic acid, were decreased in V-F5, V-F10 and V-F15 samples with increasing FO concentration $(p<0.05)$. Conversely, palmitic acid was increased with increasing FO concentration. On the other hand, unsaturated fatty acids, mainly EPA and DHA were significantly increased in mayonnaise prepared with VCO/FO blends as the FO ratio increased.

After storage of 30 days, the different fatty acid profiles were observed in all samples, compared to those found at day 0. Fatty acids, particularly lauric acid, myristic acid, DHA and EPA were decreased after 30 days of storage ( $\mathrm{p}<0.05)$. Conversely, linoleic acid, oleic acid, palmitic acid were increased after 30 days of storage $(p<0.05)$. The changes in fatty acid profile might be owing to the microorganisms or oxidative and hydrolytic enzymes in eggs (Karas et al., 2002). It was postulated that hydrolytic enzyme was able to cleave ester bond from glycerol backbone and release free fatty acids. This result was in concomitant with FFA content, which significantly increased after the storage of 30 days for all the samples (Figure 1). Moreover, lipid oxidation also contributes to the changes in fatty acid composition. After the 30 days of storage, changes in fatty acid profile of unsaturated fatty acids were observed. The results were coincidental with the increased oxidation of lipids after 30 days of storage as observed by the increases in PV, TBARS, AnV and totox value of all samples (Figure 2 A, B, C, D). The results suggested that changes in fatty acid compositions were mainly governed by hydrolysis and oxidation process during the extended storage.

\subsection{Volatile compounds}

Selected volatile compounds in V-F10 sample at day 0 and day 30 of storage at ambient temperature are shown in Table 3. Generally, volatile compounds noticed in mayonnaise at day 0 were lower in abundance than those found at 30 days. At day 0 of storage, hexanal was found as the major compound in the sample. Hexanal has been reported as a good indicator of lipid oxidation (Fuller et al., 1992). The result indicated that oxidation occurred before or during mayonnaise preparation. Other aldehydes including 3-methyl-butanal, pentanal, benzaldehyde, heptenal, propanal, (E, E)-2,4heptadienal and octanal were also found at the low levels. Hexanal and heptenal were major compounds, which contributed to rancid odor and fishy odor (Yarnpakdee et al., 2012). Moreover, volatile alcohols (1-pentanol and 1cyclobutylcyclopropanol) and furans (2-ethylfuran and 2-pentyl-furan) were found at low abundance at day 0 . However, ketones were not detected at day 0 and 30 .

After storage of 30 days, higher formation of volatile compounds was noticeable. Aldehydes were the most prominent volatiles detected in the samples. Aldehydes, ketones and alcohols have been known to be related with oxidation of lipids (Sae-leaw and Benjakul, 2014), which might occur during storage. Furans were increased after 30 days of storage. Furans and their derivatives such as 2-ethyl-furan and 2pentyl-furan are generated by the decomposition of hydroperoxide of EPA and DHA (Maqsood and Benjakul, 2011). The results were in agreement with the increases in PV and decreases in PUFA in V-F10 sample. DHA and EPA are prone to oxidation and may cause offflavor in mayonnaise samples owing to low sensory threshold values of oxidation products (Depree and Savage, 2001). 
Table 2. Fatty acid profile of mayonnaise containing different oils at different storage time.

\begin{tabular}{|c|c|c|c|c|c|c|c|c|c|c|}
\hline \multirow{2}{*}{ Fatty acids (g/100 g oil) } & \multicolumn{2}{|c|}{$\mathbf{S}$} & \multicolumn{2}{|c|}{$\mathbf{V}$} & \multicolumn{2}{|c|}{ V-F5 } & \multicolumn{2}{|c|}{ V-F10 } & \multicolumn{2}{|c|}{ V-F15 } \\
\hline & Day 0 & Day 30 & Day 0 & Day 30 & Day 0 & Day 30 & Day 0 & Day 30 & Day 0 & Day 30 \\
\hline C6:0 (Caproic) & ND & ND & $0.45 \pm 0.00 \mathrm{a}$ & $0.38 \pm 0.00 \mathrm{~b}$ & $0.41 \pm 0.00 \mathrm{a}$ & $0.37 \pm 0.00 \mathrm{~b}$ & $0.38 \pm 0.00 \mathrm{a}$ & $0.35 \pm 0.00 \mathrm{~b}$ & $0.36 \pm 0.00 \mathrm{a}$ & $0.33 \pm 0.00 \mathrm{~b}$ \\
\hline C8:0 (Caprylic) & ND & ND & $6.34 \pm 0.00 \mathrm{a}$ & $5.91 \pm 0.00 b$ & $5.91 \pm 0.01 \mathrm{a}$ & $5.69 \pm 0.00 \mathrm{~b}$ & $5.53 \pm 0.00 \mathrm{a}$ & $5.35 \pm 0.01 b$ & $5.18 \pm 0.00 \mathrm{a}$ & $5.05 \pm 0.00 \mathrm{~b}$ \\
\hline C10:0 (Capric) & ND & ND & $5.49 \pm 0.01 \mathrm{a}$ & $5.32 \pm 0.00 \mathrm{~b}$ & $5.15 \pm 0.00 \mathrm{a}$ & $5.09 \pm 0.00 \mathrm{~b}$ & $4.83 \pm 0.00 \mathrm{a}$ & $4.78 \pm 0.00 b$ & $4.52 \pm 0.00 \mathrm{a}$ & $4.48 \pm 0.00 b$ \\
\hline C12:0 (Lauric acid) & $0.30 \pm 0.00 \mathrm{a}$ & $0.07 \pm 0.00 \mathrm{~b}$ & $47.05 \pm 0.10 \mathrm{a}$ & $43.09 \pm 0.03 b$ & $44.14 \pm 0.02 \mathrm{a}$ & $41.62 \pm 0.20 b$ & $41.62 \pm 0.02 \mathrm{a}$ & $39.15 \pm 0.01 b$ & $38.81 \pm 0.02 \mathrm{a}$ & $36.44 \pm 0.01 \mathrm{~b}$ \\
\hline C14:0 (Myristic acid) & $0.23 \pm 0.00 \mathrm{a}$ & $0.1 \pm 0.00 \mathrm{~b}$ & $19.57 \pm 0.05 \mathrm{a}$ & $16.66 \pm 0.00 \mathrm{~b}$ & $18.61 \pm 0.01 \mathrm{a}$ & $16.65 \pm 0.01 b$ & $17.80 \pm 0.01 \mathrm{a}$ & $15.90 \pm 0.02 b$ & $16.81 \pm 0.00 \mathrm{a}$ & $14.99 \pm 0.01 \mathrm{~b}$ \\
\hline C15:0 (Pentadecanoic) & ND & ND & ND & ND & ND & $0.04 \pm 0.00$ & $0.06 \pm 0.00 \mathrm{~b}$ & $0.07 \pm 0.00 \mathrm{a}$ & $0.09 \pm 0.00 \mathrm{a}$ & $0.09 \pm 0.00 \mathrm{a}$ \\
\hline C16:0 (Palmitic) & $11.16 \pm 0.00 \mathrm{a}$ & $10.63 \pm 0.00 \mathrm{~b}$ & $9.55 \pm 0.01 \mathrm{~b}$ & $10.00 \pm 0.00 \mathrm{a}$ & $10.49 \pm 0.01 b$ & $10.93 \pm 0.01 \mathrm{a}$ & $11.15 \pm 0.00 \mathrm{~b}$ & $11.66 \pm 0.01 \mathrm{a}$ & $11.88 \pm 0.00 \mathrm{~b}$ & $12.37 \pm 0.02 \mathrm{a}$ \\
\hline C16:1 (Palmitoleic) & $0.24 \pm 0.00 \mathrm{a}$ & $0.08 \pm 0.00 \mathrm{~b}$ & ND & $0.20 \pm 0.00$ & $0.37 \pm 0.00 \mathrm{~b}$ & $0.51 \pm 0.00 \mathrm{a}$ & $0.64 \pm 0.00 \mathrm{~b}$ & $0.82 \pm 0.00 \mathrm{a}$ & $0.95 \pm 0.00 b$ & $1.09 \pm 0.00 \mathrm{a}$ \\
\hline C17:0 (Heptadecanoic) & $0.10 \pm 0.00 \mathrm{a}$ & $0.09 \pm 0.00 \mathrm{~b}$ & ND & ND & ND & ND & $0.062 \pm 0.00 \mathrm{~b}$ & $0.07 \pm 0.00 \mathrm{a}$ & $0.09 \pm 0.00 b$ & $0.10 \pm 0.00$ \\
\hline C18:0 (Stearic) & $4.17 \pm 0.00 \mathrm{a}$ & $4.12 \pm 0.00 \mathrm{~b}$ & $3.55 \pm 0.00 \mathrm{a}$ & $3.45 \pm 0.00 \mathrm{~b}$ & $3.70 \pm 0.00 \mathrm{a}$ & $3.58 \pm 0.00 \mathrm{~b}$ & $3.80 \pm 0.00 \mathrm{a}$ & $3.69 \pm 0.00 \mathrm{a}$ & $3.91 \pm 0.00 \mathrm{a}$ & $3.85 \pm 0.00 \mathrm{~b}$ \\
\hline C18:1 cis 9 (Oleic) & $23.47 \pm 0.00 b$ & $24.18 \pm 0.00 \mathrm{a}$ & $5.78 \pm 0.00 \mathrm{~b}$ & $9.25 \pm 0.00 \mathrm{a}$ & $7.26 \pm 0.2 b$ & $10.01 \pm 0.10 \mathrm{a}$ & $8.54 \pm 0.00 \mathrm{~b}$ & $11.02 \pm 0.02 \mathrm{a}$ & $9.68 \pm 0.00 \mathrm{~b}$ & $11.98 \pm 0.00 \mathrm{a}$ \\
\hline C18:2 cis 9,12 (Linoleic) & $50.07 \pm 0.00 \mathrm{~b}$ & $52.90 \pm 0.00 \mathrm{a}$ & $1.13 \pm 0.00 \mathrm{~b}$ & $4.07 \pm 0.01 \mathrm{a}$ & $1.85 \pm 0.00 \mathrm{~b}$ & $3.08 \pm 0.00 \mathrm{a}$ & $2.38 \pm 0.00 \mathrm{~b}$ & $3.42 \pm 0.00 \mathrm{a}$ & $2.99 \pm 0.00 \mathrm{~b}$ & $3.99 \pm 0.00 \mathrm{a}$ \\
\hline C20:0 (Arachidic) & $0.32 \pm 0.00 \mathrm{~b}$ & $0.34 \pm 0.00 \mathrm{a}$ & $0.10 \pm 0.00 \mathrm{a}$ & $0.09 \pm 0.00 \mathrm{~b}$ & $0.11 \pm 0.00 \mathrm{a}$ & $0.10 \pm 0.00 \mathrm{~b}$ & $0.13 \pm 0.00 \mathrm{a}$ & $0.10 \pm 0.00 \mathrm{~b}$ & $0.13 \pm 0.00 \mathrm{a}$ & $0.12 \pm 0.00 \mathrm{~b}$ \\
\hline $\begin{array}{l}\text { C18:3 cis } 6,9,12 \text { gamma } \\
\text { (gramma-Linolenic) }\end{array}$ & $0.49 \pm 0.00 b$ & $0.53 \pm 0.00 \mathrm{a}$ & ND & ND & ND & ND & $0.06 \pm 0.00 \mathrm{~b}$ & $0.07 \pm 0.00 \mathrm{a}$ & $0.10 \pm 0.00 \mathrm{a}$ & $0.10 \pm 0.00 \mathrm{a}$ \\
\hline $\begin{array}{l}\text { C20:1 cis } 11 \text { (cis-11- } \\
\text { Eicosenoic) }\end{array}$ & $0.47 \pm 0.00 \mathrm{~b}$ & $0.50 \pm 0.00 \mathrm{a}$ & ND & ND & $0.092 \pm 0.00 \mathrm{a}$ & $0.09 \pm 0.00 \mathrm{~b}$ & $0.06 \pm 0.00 \mathrm{a}$ & $0.05 \pm 0.00 \mathrm{~b}$ & $0.08 \pm 0.00 \mathrm{a}$ & $0.08 \pm 0.00 \mathrm{a}$ \\
\hline $\begin{array}{l}\text { C18:3 cis } 9,12,15 \text { alpha } \\
\text { (alpha-Linolenic) }\end{array}$ & $5.28 \pm 0.00 \mathrm{~b}$ & $5.58 \pm 0.00 \mathrm{a}$ & ND & $0.24 \pm 0.00$ & $0.09 \pm 0.00 b$ & $0.13 \pm 0.00 \mathrm{a}$ & $0.16 \pm 0.00 \mathrm{~b}$ & $0.19 \pm 0.00 \mathrm{a}$ & $0.23 \pm 0.00 \mathrm{~b}$ & $0.26 \pm 0.00 \mathrm{a}$ \\
\hline C20:0 (Docosanoic) & $0.36 \pm 0.00 \mathrm{~b}$ & $0.38 \pm 0.00 \mathrm{a}$ & ND & ND & ND & ND & ND & ND & ND & ND \\
\hline $\begin{array}{l}\text { C20:2 cis } 11,14 \text { (cis- } 11,14- \\
\text { Eicosadienoic) }\end{array}$ & ND & ND & ND & ND & ND & ND & $0.11 \pm 0.00 \mathrm{~b}$ & $0.12 \pm 0.00 \mathrm{a}$ & $0.16 \pm 0.00 \mathrm{~b}$ & $0.17 \pm 0.00 \mathrm{a}$ \\
\hline $\begin{array}{l}\mathrm{C} 20: 3 \text { cis } 8,11,14 \text { (cis- } \\
8,11,14 \text {-Eicosatrienoic) }\end{array}$ & ND & ND & ND & ND & ND & ND & ND & ND & $0.06 \pm 0.00 \mathrm{a}$ & $0.06 \pm 0.00 \mathrm{a}$ \\
\hline C22:1 cis 13 (Erucanoic) & ND & ND & ND & ND & ND & ND & $0.06 \pm 0.00 \mathrm{a}$ & $0.06 \pm 0.00 \mathrm{a}$ & $0.09 \pm 0.00 \mathrm{a}$ & $0.09 \pm 0.00 \mathrm{a}$ \\
\hline C23:0 (Tricosanoic) & ND & ND & ND & ND & $0.06 \pm 0.00 \mathrm{~b}$ & $0.10 \pm 0.00 \mathrm{a}$ & $0.12 \pm 0.00 \mathrm{~b}$ & $0.16 \pm 0.00 \mathrm{a}$ & $0.18 \pm 0.00 b$ & $0.23 \pm 0.00 \mathrm{a}$ \\
\hline C24:0 (Lignoceric) & $0.11 \pm 0.00 \mathrm{~b}$ & $0.12 \pm 0.00 \mathrm{a}$ & ND & ND & ND & ND & ND & ND & ND & ND \\
\hline
\end{tabular}


Patil and Benjakul/ Carpathian Journal of Food Science and Technology, 2020, 12(1), 135-147

C20:5 cis 5,8,11,14,17 EPA

(cis-5,8,11,14,17-

ND

ND

ND

ND

$0.21 \pm 0.00 \mathrm{a}$

$0.19 \pm 0.00 \mathrm{~b}$

$0.39 \pm 0.00 \mathrm{a}$

$0.38 \pm 0.00 \mathrm{~b}$

$0.59 \pm 0.00 \mathrm{a}$

$0.57 \pm 0.00 \mathrm{~b}$

C22:6 cis 4,710,13,16,19

DHA (cis-4,710,13,16,19-

ND ND

ND

ND

$0.42 \pm 0.00 \mathrm{a}$

$0.38 \pm 0.00 \mathrm{~b}$

$0.75 \pm 0.00 \mathrm{a}$

$0.73 \pm 0.00$

$1.13 \pm 0.00 \mathrm{a}$

$1.10 \pm 0.00 \mathrm{~b}$

ND: not detected. S: mayonnaise containing soybean oil, V: mayonnaise containing virgin coconut oil (VCO), V-F5: mayonnaise containing VCO $(95 \%)+$ fish oil $(5 \%)$, V-F10: mayonnaise containing VCO $(90 \%)+$ fish oil $(10 \%)$, V-F15: mayonnaise containing VCO $(85 \%)+$ fish oil $(15 \%)$ Values are mean \pm standard deviation $(n=3)$. Different lowercase letters in the same row under the same sample indicate significant difference $(\mathrm{p}<0.05)$. 
Table 3. Volatile compounds in mayonnaise containing VCO/FO (90:10) blend at day 0 and day 30 of storage at room temperature

\begin{tabular}{lcc}
\hline \multirow{2}{*}{ Volatile compounds } & Peak area (Abundance) $\mathbf{x 1 0}$ \\
\cline { 2 - 3 } Furans & day $\mathbf{~}$ & day $\mathbf{3 0}$ \\
\hline 2-Ethyl-furan & & \\
2-Pentyl-furan & 8.15 & 183.69 \\
Aldehydes & 5.70 & 79.53 \\
\hline Propanal & & \\
2-Methyl-butanal & 4.39 & 7.52 \\
3-Methyl-butanal & $\mathrm{ND}$ & $\mathrm{ND}$ \\
Pentanal & 11.15 & 63.31 \\
Hexanal & 7.81 & 283.20 \\
(E)-2-Hexenal & 113.16 & 682.89 \\
Heptenal & $\mathrm{ND}$ & $\mathrm{ND}$ \\
(E, E)-2,4-heptadienal & 4.78 & 68.49 \\
Octanal & 2.37 & 11.06 \\
(E)-2-decenal & 1.51 & 11.15 \\
Benzaldehyde & $\mathrm{ND}$ & $\mathrm{ND}$ \\
Alcohols & 6.38 & 35.49 \\
\hline 1-Cyclobutylcyclopropanol & & \\
1-Pentanol & 3.40 & $\mathrm{ND}$ \\
(Z)-2-pentenol & 10.59 & 3.68 \\
(E)-2-hexenol & $\mathrm{ND}$ & $\mathrm{ND}$ \\
1-Methyl-4-(1-methylethenyl)-cyclohexanol & $\mathrm{ND}$ & $\mathrm{ND}$ \\
1-Octen-3-ol & 1.70 & $\mathrm{ND}$ \\
(Z)-1,5-octadien-3-ol & $\mathrm{ND}$ & $\mathrm{ND}$ \\
\hline
\end{tabular}

ND: not detectable

\section{Conclusions}

VCO could be used instead of SO for the production of mayonnaise. Addition of FO up to $10 \%$ in $\mathrm{VCO} / \mathrm{FO}$ blend could yield the mayonnaise with sensorial acceptability. However, masking agent or potential removal of off-odor was still required when FO higher than $10 \%$ was added. Type of oil used for preparation of mayonnaise affected FFA content of resulting mayonnaise. Oxidative stability varied with mayonnaises containing different oils. Mayonnaise sample with VCO was less prone to lipid oxidation throughout storage of 30 days. Overall, VCO in combination with FO at an appropriate ratio could be used instead of $\mathrm{SO}$ to prepare a functional mayonnaise with increased oxidative stability.

\section{Acknowledgement}

Prince of Songkla University (Grant No. AGR6302013N) was acknowledged.

\section{References}

Abu-Salem, F.M. and Abou-Arab, A.A. (2008). Chemical, microbiological and sensory evaluation of mayonnaise prepared from ostrich eggs. Grasas y aceites, 59(4), 352360.

Alemán, M., Bou, R., Guardiola, F., Durand, E., Villeneuve, P., Jacobsen, C. and Sørensen, A.D.M. (2015). Antioxidative effect of 
lipophilized caffeic acid in fish oil enriched mayonnaise and milk. Food Chemistry, 167: 236-244.

Bligh, E.G. and Dyer, W.J. (1959). A rapid method of total lipid extraction and purification. Canadian Journal of Biochemistry and Physiology, 37(8): 911917.

Choe, E. and Min, D.B. (2006). Mechanisms and factors for edible oil oxidation. Comprehensive Reviews in Food Science and Food Safety, 5(4): 169-186.

Coupland, J.N. and McClements, D.J. (1996). Lipid oxidation in food emulsions. Trends in Food Science and Technology, 7(3): 83-91.

Depree, J. and Savage, G. (2001). Physical and flavour stability of mayonnaise. Trends in Food Science and Technology, 12(5-6): 157163.

Enig, M., Pallansch, L., Sampugna, J. and Keeney, M. (1983). Fatty acid composition of the fat in selected food items with emphasis on trans components1. Journal of the American Oil Chemists' Society, 60(10): 1788-1795.

Fuller, C.J., Faulkner, H., Bendich, A., Parker, R.S. and Roe, D.A. (1992). Effect of $\beta$ carotene supplementation on photosuppression of delayed-type hypersensitivity in normal young men. The American Journal of Clinical Nutrition, 56(4): 684-690.

Gorji, S.G., Smyth, H.E., Sharma, M. and Fitzgerald, M. (2016). Lipid oxidation in mayonnaise and the role of natural antioxidants: A review. Trends in Food Science and Technology, 56: 88-102.

Hartvigsen, K., Lund, P., Hansen, L.F. and Hølmer, G. (2000). Dynamic headspace gas chromatography/mass spectrometry characterization of volatiles produced in fish oil enriched mayonnaise during storage. Journal of Agricultural and Food Chemistry, 48(10): 4858-4867.

Huang, L., Wang, T., Han, Z., Meng, Y. and Lu, X. (2016). Effect of egg yolk freezing on properties of mayonnaise. Food Hydrocolloids, 56: 311-317.
Huimin, X., Lin, L., Shilin, G., Elfalleh, W., Shenghua, H., Qinghai, S. and Ying, M. (2014). Formation, stability, and properties of an algae oil emulsion for application in UHT milk. Food and Bioprocess Technology, 7(2): 567-574.

Jacobsen, C. (1999). Sensory impact of lipid oxidation in complex food systems. European Journal of Lipid Science and Technology, 101(12): 484-492.

Jacobsen, C., Hartvigsen, K., Thomsen, M. K., Hansen, L.F., Lund, P., Skibsted, L.H., Hølmer, G., Adler-Nissen, J. and Meyer, A.S. (2001). Lipid oxidation in fish oil enriched mayonnaise: calcium disodium ethylenediaminetetraacetate, but not gallic acid, strongly inhibited oxidative deterioration. Journal of Agricultural and Food Chemistry, 49(2): 1009-1019.

Karas, R., Skvarča, M. and Žlender, B. (2002). Sensory quality of standard and light mayonnaise during storage. Food Technology and Biotechnology, 40(2): 119127.

Kishk, Y. and Elsheshetawy, H.E. (2013). Effect of ginger powder on the mayonnaise oxidative stability, rheological measurements, and sensory characteristics. Annals of Agricultural Sciences, 58(2): 213220.

Li, C.-Y., Kim, H.-W., Li, H., Lee, D.-C. and Rhee, H.-I. (2014). Antioxidative effect of purple corn extracts during storage of mayonnaise. Food Chemistry, 152: 592-596.

Maqsood, S. and Benjakul, S. (2011). Retardation of haemoglobin-mediated lipid oxidation of Asian sea bass muscle by tannic acid during iced storage. Food Chemistry, 124(3): 1056-1062.

Martinez-Tome, M., Jimenez, A.M., Ruggieri, S., Frega, N., Strabbioli, R. and Murcia, M.A. (2001). Antioxidant properties of Mediterranean spices compared with common food additives. Journal of Food Protection, 64(9): 1412-1419.

McClements, D. and Decker, E. (2000). Lipid oxidation in oil-in-water emulsions: Impact of molecular environment on chemical 
reactions in heterogeneous food systems. Journal of Food Science, 65(8): 1270-1282.

Meilgaard, M.C., Carr, B.T. and Civille, G.V. (2006). Sensory evaluation techniques. Boca Raton: CRC press.

Meyer, A.S. and Jacobsen, C. (1996). Fate of the synergistic antioxidant system ascorbic acid, lecithin, and tocopherol in mayonnaise: partition of ascorbic acid. Journal of Food Lipids, 3(2): 139-147.

Muhammed, M., Domendra, D., Muthukumar, S., Sakhare, P. and Bhaskar, N. (2015). Effects of fermentatively recovered fish waste lipids on the growth and composition of broiler meat. British Poultry Science, 56(1): 79-87.

Osborn, H.T. and Akoh, C.C. (2004). Effect of emulsifier type, droplet size, and oil concentration on lipid oxidation in structured lipid-based oil-in-water emulsions. Food Chemistry, 84(3): 451-456.

Patil, U., Benjakul, S., Prodpran, T., Senphan, T. and Cheetangdee, N. (2016). Characteristics and quality of virgin coconut oil as influenced by maturity stages. Carpathian Journal of Food Science and Technology, 8(4): 103-115.

Patil, U. and Benjakul, S. (2018). Coconut milk and coconut oil: their manufacture associated with protein functionality. Journal of Food Science, 83(8): 2019-2027.

Patil, U. and Benjakul, S. (2019a). Physical and textural properties of mayonnaise prepared using virgin coconut oil/fish oil blend. Food Biophysics, 14(3): 260-268.

Patil, U. and Benjakul, S. (2019b). Use of protease from seabass pyloric caeca in combination with repeated freeze-thawing cycles increases the production efficiency of virgin coconut oil. European Journal of Lipid Science and Technology, 121(5): 1800460.

Sae-leaw, T. and Benjakul, S. (2014). Fatty acid composition, lipid oxidation, and fishy odour development in seabass (Lates calcarifer) skin during iced storage. European Journal of Lipid Science and Technology, 116(7): 885-894.
Sae-leaw, T. and Benjakul, S. (2017). Lipids from visceral depot fat of Asian seabass (Lates calcarifer): Compositions and storage stability as affected by extraction methods. European Journal of Lipid Science and Technology, 119(11): 1-10.

Shahidi, F. and Zhong, Y. (2005). Bailey's Industrial Oil and Fat Products. $6^{\text {th }}$ ed. Hoboken, New Jersey: John Wiley and Sons, Inc.

Steel, R. and Torrie, J. (1980). Principles and practices of statistics. New York, USA: McGraw Book Coy Inc.

Takeungwongtrakul, S., Benjakul, S. and Aran, H. (2012). Lipids from cephalothorax and hepatopancreas of Pacific white shrimp (Litopenaeus vannamei): Compositions and deterioration as affected by iced storage. Food Chemistry, 134(4): 2066-2074.

Yarnpakdee, S., Benjakul, S., Nalinanon, S. and Kristinsson, H.G. (2012). Lipid oxidation and fishy odour development in protein hydrolysate from Nile tilapia (Oreochromis niloticus) muscle as affected by freshness and antioxidants. Food Chemistry, 132(4): 1781-1788.

Zhang, W., Xiao, S. and Ahn, D.U. (2013). Protein oxidation: basic principles and implications for meat quality. Critical Reviews in Food Science and Nutrition 53(11): 1191-1201. 